\title{
MANAGEMENT OF ACCIDENTAL THERMAL BURNS DUE TO BURNING OF HOUSEHOLD WASTE IN RURAL AREAS OF KERALA: AN INSTITUTIONAL STUDY.
}

\section{Dr Hemang Sanghvi \\ Dr Geetanjali Remesh \\ Dr Pradeoth Mukundan Korambayil * \\ ABSTRACT}

Mbbs, DNB, Mch Plastic Surgery, Assistant Professor,Department of Plastic and Reconstructive surgery, Jubilee mission medical college Thrissur (Kerala), India.

Junior Resident, Department of Plastic and Reconstructive surgery, Jubilee mission medical college, Thrissur (Kerala), India.

Mbbs, Mbbs, Ms, MCh Plastic Surgery, Associate professor,Department of Plastic and Reconstructive surgery, Jubilee mission medical college ,Thrissur (Kerala), India. * Corresponding Author

Aim: The aim of this study was to find out epidemiology and treatment of thermal injuries due to burning of household waste, a common practice in rural areas of Kerala.

Material And Methods: Prospective study was carried out in the department of burns and plastic surgery from 1 st January 2018 to 29th February 2020. All patients with history of burns due to burning of household waste in rural areas of Kerala during this period were included in our study.Patients were managed with conservative management or surgical debridement and split thickness skin graft. Hyperbaric oxygen therapy was given as an adjunct.

Results: A total of 670 patients were admitted in our burns department out of which 75 patients were due to burning of household waste. Thirty-three patients were male and Forty-two patients were female. Most of them had around 10-30 percent thermal burns. Mortality was 6.6 percent. Most of the burns involved lower extremity and upper extremity.

Conclusions: Burning of household waste is a common practice in outskirts of Kerala which leads to accidental burns resulting in a significant number of admissions in our hospital. Proper awareness and facility for waste disposal is needed to avoid burn injuries due to burning of waste in rural areas.

\section{KEYWORDS : Household Waste, Hyperbaric Oxygen Therapy, Thermal Burns.}

\section{INTRODUCTION}

Open burning of waste leading to accidental thermal injuries is a global issue more common in developing countries like India ${ }^{(1)}$.It impacts all socioeconomic groups, all regions and all cultures ${ }^{(2)}$. It is a process in which unwanted products, byproducts and materials are burned typically at low temperatures and in an uncontrolled manner ${ }^{(1)}$. Developed countries have less incidence of open waste burning ${ }^{(1)}$.Africa has $46 \%$ collection coverage, and South Asia has 65\% collection coverage. ${ }^{(1)}$ These regions have the greatest percentage of residential open burning of waste. China, India and Brazil are large generators of waste that still openly burn waste ${ }^{(1)}$. These countries do not have the resources necessary to stop it. ${ }^{(2,3)}$ Developing proper program, for waste disposal mechanism is difficult in less economically developing countries due to lack of infrastructure, financial and technological reasons $s^{(4,5)}$.It is still more common problem in rural areas were proper facilities for waste disposal are not available ${ }^{(6)}$. It is a common practice to dispose waste by burning it outside the house in rural areas of Kerala. People use kerosene or any cheap gasoline product to dispose household waste outside the house and develop accidental thermal injuries over the body. ${ }^{(7)}$ This practice is common because it is fast, inexpensive and effective way to reduce waste. These injuries have specific pattern of burn involvement over the body ${ }^{(7)}$. It has specific sex distribution and may have seasonal impact. ${ }^{(8)}$ It results in significant morbidity and mortality resulting in significant loss of work pay and impacts the quality of life ${ }^{(7)}$. Lack of awareness is also a major problem in rural areas. ${ }^{(9,10)}$ These injuries are avoidable injuries. Proper facilities such as improved collection, improved disposal, recycling can avoid accidental burn injuries ${ }^{(11,12)}$.Thepurpose of this study was to find out patients admitted in our institution due to burning of household waste and management of same patients.

\section{AIMS AND OBJECTIVE:}

1.Management of accidental thermal burns due to burning of household waste.

2. To create awareness and educate among general public to avoid trash burns since these are avoidable injuries.

3.Proper methods for waste disposal should be made available to avoid such burn injuries.

\section{MATERIAL AND METHODS}

The prospective study was carried out in Plastic surgery and Burns department, from $1^{\text {st }}$ January 2018 to $29^{\text {th }}$ February 2020 in a tertiary referral centre in South India.

\section{Inclusion Criteria:}

1.All patients admitted in our burns or treated as outpatient department during the time period $1^{\text {st }}$ January 2018 to $29^{\text {th }}$ February 2020 with history of burns due to burning of household waste were included in our study.

2.Patient with above history who gave consent were included in our study group.

\section{Exclusion Criteria:}

1.Patient who had burns due to other cause were excluded from our study group.

2.Patient who came from urban areas were excluded from our study group.

The ethical committee clearance was taken for the study. All patients were treated according to standard burns protocol on admission. Patients were treated with conservative management. Hyperbaric oxygen therapy was given as an adjunct for five days. Patients who did not respond to conservative management were managed surgically by tangential excision and split thickness skin graft. Results were evaluated as per the data collected about mortality, morbidity and treatment of burn patients.

\section{RESULTS}

A total of 670 patients were admitted during the time period $l^{\text {st }}$ JANUARY 2018 to $29^{\text {th }}$ February 2020 out of which 75 patients 
were due to burning of household waste (Table 1).33 patients admitted were males and 42 patients were females in our study group (Table 1). Male to Female ratio was 0.78 . Majority belong to 41-50 age groups (Table 4). Most of the patient admitted had burns around $10-30 \%$ burns of body area in our study group (Tablel). Majority of burns involved lower extremity, foot and upper extremity in our study group (Table 5). Forty-one patients were managed conservatively and Twenty-nine patients were managed with Tangential excision and split thickness skin graft (Table 1).Five patients died. They had more than 50 percent of burns involvement in our study group (Tablel).Mean duration of stay was 2 to 3 weeks with follow up thereafter was round 3 weeks (Table 2,3 ).

Case 1: A 53 year female was admitted with $11 \%$ TBSA burns involving right forearm and lower face and neck (Figure 1). She underwent wound debridement and dressing on dayl and hyperbaric oxygen therapy was given for 6 consecutive days as an adjunct (Figurela, lb, lc, ld). Patient had complete epithelisation on day7 (figure ld).

Case 2: A 63 year male patient was admitted with 27 TBSA burns involving right leg and lower abdomen (figure 2). He underwent wound debridement and dressing on day $l$ (Figure $2 \mathrm{~b})$ followed by dressing alternate day (figure 2b, 2c,2d). Hyperbaric oxygen therapy was given as adjunct for 5 days. Right leg had second degree burns managed with tangential excision and skin grafting on day 6 (figure $2 \mathrm{e}$ ).

Case3:A 80 year female admitted with 25 TBSA burns involving back and right gluteal region she was unfit to undergo any surgery was managed with conservative management and hyperbaric oxygen therapy was given as adjunct for two weeks (figure3). Allografting was done on her back and gluteal region on day 14 (figure 3c). Later her graft was rejected and was managed conservatively wound healed by secondary intention (figure 3d).

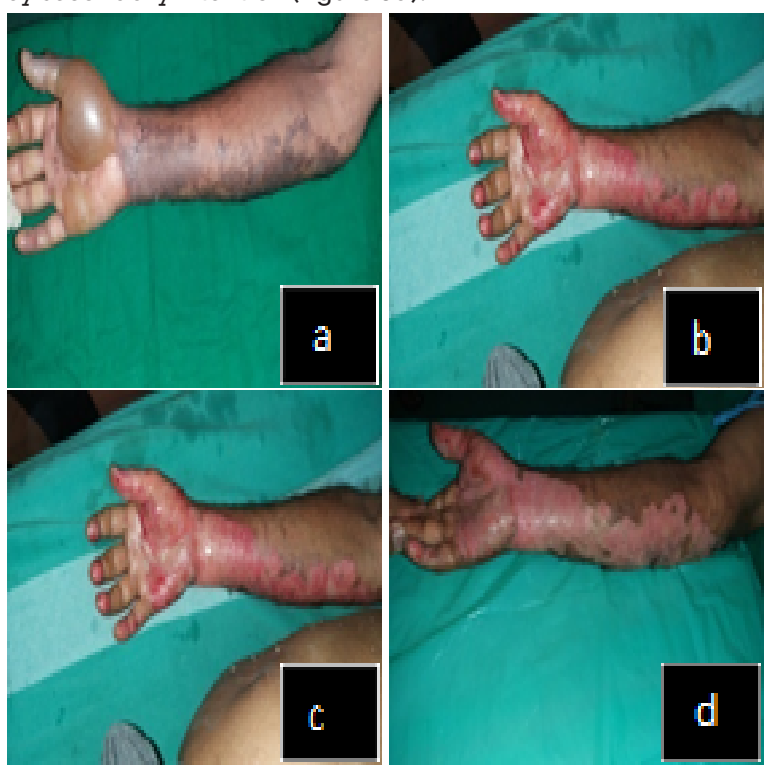

Figurel: (a) Second degree superficial burns involving volar aspect of forearm and hand, (b) After debridement dayl, (c) After dressing day 3 and three session of hyperbaric oxygen therapy as adjunct, (d) After dressing day7 and six session of hyperbaric oxygen therapy as adjunct .
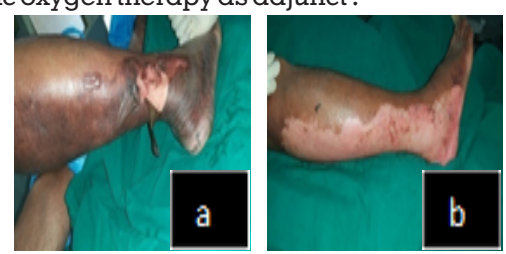

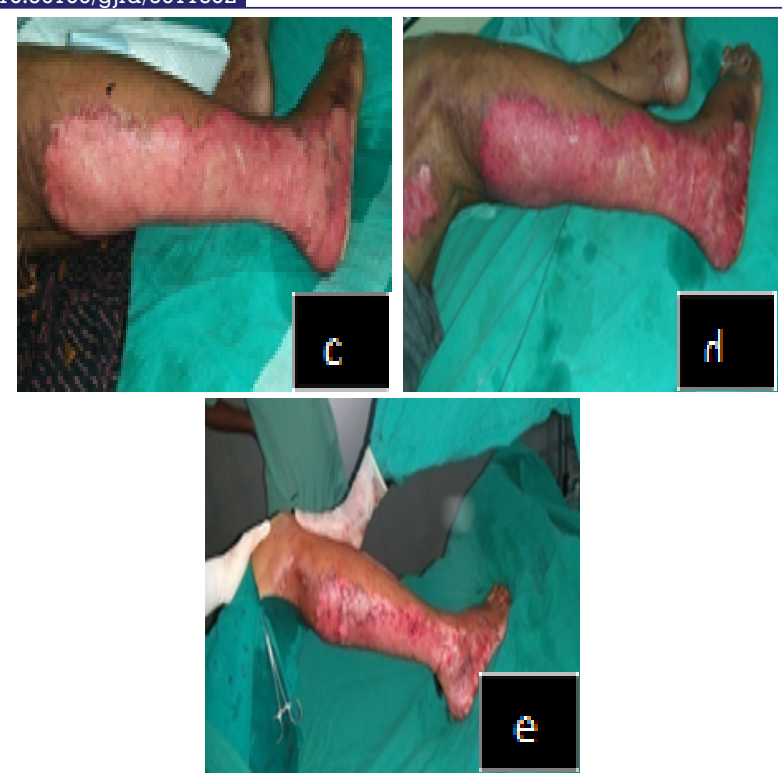

Figure 2: (a) Second degree deep burns involving right leg on the day of admission, (b) After debridement dayl, (c) After dressing day 3 and three session of hyperbaric oxygen therapy as an adjunct, (d) After dressing day 5 and five session of hyperbaric oxygen therapy as an adjunct, (e) After day6 tangential excision and split thickness skin graft.

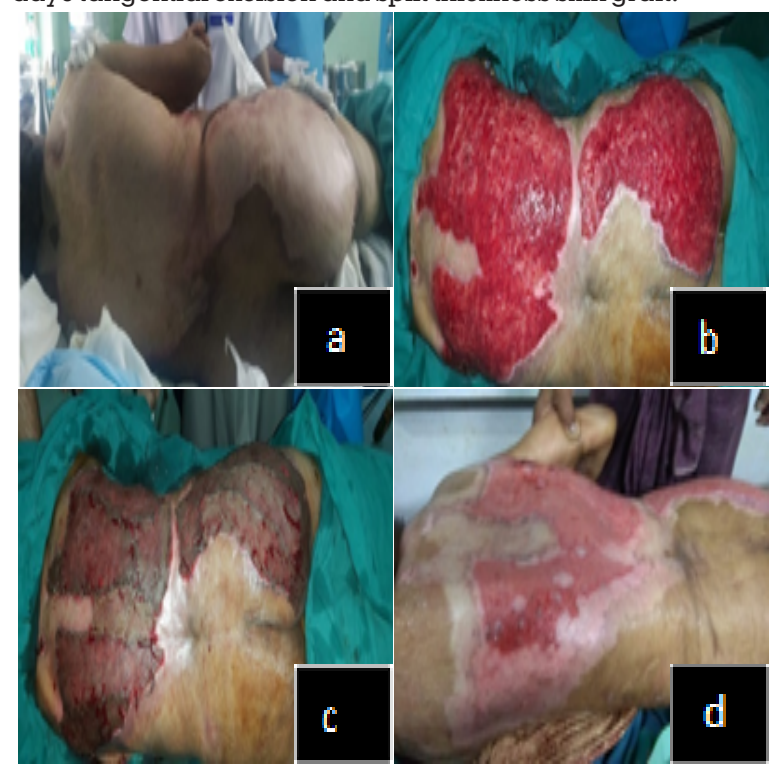

Figure 3: ( $\alpha$ ) Third degree deep burns involving back and right gluteal region managed conservatively with debridement and hyperbaric oxygen therapy as an adjunct day l, (b) Day 14 conservative management and hyperbaric oxygen therapy as an adjunct, (c) Allografting done on back and right gluteal region day 16, (d) Late post operative picture after one month of conservative management as patient was unstable.

\section{DISCUSSION:}

Waste disposal by burning outside house is a common habit in rural community ${ }^{[1,2]}$.Proper facility for disposing waste is also not available in rural areas ${ }^{[3]}$. Insufficient funding in developing countries to dispose waste is also a major issue ${ }^{[3,4]}$. Lack of awareness is also a major issue. Proper education is needed to avoid accidental thermal injuries due to burning of waste. Preventive measures should be taken by involving government, social media, NGO, to avoid burn injuries.It require coordinated efforts at panchayat, district, talukas and tertiary levels ${ }^{[5]}$.Burning of household wasteis also common problem in rural areas of Kerala. Itresults in accidental 
thermal injuries which cause significant admission in our hospital.Out of total (670) burn admission, (75) patients admitted were due to burning of household waste (Table l). It results in $11.3 \%$ admissions in our hospital.Females were more involved then male in our study group (Table 1).Majority belong middle age group around $41-50$ years (Table4).These burn injuries involve mostly lower limb, foot and upper limb where fire is caught accidentally in clothes(Table 5).Most of burns involved are second degree superficial to deep burns.Superficial burns patients responded to conservative management. They recovered in 7 to 10 days and required 1 to 2 week follow up thereafter (Table 2, 3). Deep burns patients required aggressive treatment with tangential excision and split thickness skin grafting. They required 3 to 4 weeks of admission and 3 to 4 week of follow up thereafter (Table 2, 3). Hyperbaric oxygenation maintains adequate oxygenation in the burned areas protecting the tissue from colonization or infection by anaerobic organism. In animal studies, it has been demonstrated that the degree of intestinal bacterial translocation after a severe burn wound is significantly reduced when $\mathrm{HBO}$ therapy is administered ${ }^{[13)}$. A significantly lower incidence of sepsis is also found in the HBO treated group. In our study group hyperbaric oxygen therapy was given as an adjunct therapy to all patient groups. It resulted in significant decrease of edema and faster healing and lesser stay in our hospital. Five patients died in our study group as they had more than 50 percent burns did not respond to treatment.

Table 1: Data Of Number Of Patients Admitted With Burns Due To Burning Of Household Waste.

\begin{tabular}{|l|l|l|l|l|l|l|}
\hline PERCE & NUMBER & MALEFEMALE & CONSE & TANGEN & MORTA \\
NTAGE & OF & & & RVATIVE & TIAL & LITY \\
OF & PATIENTS & & & TREATM & EXCISIO & \\
BURNS & & & & ENT & $\begin{array}{l}\text { N PLUS } \\
\text { SPLIT } \\
\text { THICKN } \\
\text { ESS }\end{array}$ & \\
& & & & & & \\
& & & & & SKIN & \\
& & & & & GRAFT & \\
\hline $0-10$ & 26 & 18 & 8 & 24 & 2 & 0 \\
\hline $11-20$ & 21 & 7 & 14 & 14 & 7 & 0 \\
\hline $21-30$ & 15 & 7 & 8 & 2 & 13 & 0 \\
\hline $31-40$ & 7 & 1 & 6 & 1 & 6 & 0 \\
\hline $41-50$ & 1 & 0 & 1 & 0 & 1 & 0 \\
\hline$>50$ & 5 & 0 & 5 & 0 & 0 & 5 \\
\hline TOTAL & 75 & 33 & 42 & 41 & 29 & 5 \\
\hline
\end{tabular}

Table 2: Data Of Duration Of Stay In Hospital

\begin{tabular}{|l|l|l|l|l|}
\hline PERCENTA & NUMBER & NUMBER & NUMBER & NUMBER \\
GE OF & OF & OF & OF & OF \\
BURNS & PATIENTS & PATIENTS & PATIENTS & PATIENTS \\
& ADMITTED & ADMITTED & ADMITTED & ADMITTED \\
& FOR 1 & FOR 2 & FOR 3 & FOR 4 \\
& WEEK & WEEK & WEEK & WEEK \\
\hline $0-10$ & 10 & 1 & 0 & 0 \\
\hline $11-20$ & 7 & 9 & 5 & 0 \\
\hline $21-30$ & 0 & 2 & 10 & 3 \\
\hline $31-40$ & 0 & 1 & 3 & 3 \\
\hline $41-50$ & 0 & 0 & 0 & 1 \\
\hline$>50$ & 5 & 0 & 0 & 0 \\
\hline TOTAL & 22 & 13 & 18 & 7 \\
\hline
\end{tabular}

Table 3: Data Of Follow Up Of Patient.

\begin{tabular}{|l|l|l|l|l|}
\hline PERCENTA & NUMBER & NUMBER & NUMBER & NUMBER \\
GE OF & OF & OF & OF & OF \\
\hline
\end{tabular}

\begin{tabular}{|l|l|l|l|l|}
\hline BURNS & PATIENTS & PATIENTS & PATIENTS & PATIENTS \\
& FOR 1 & FOR 2 & FOR 3 & FOR 4 \\
& WEEK & WEEK & WEEK & WEEK \\
& FOLLOW & FOLLOW & FOLLOW & FOLLOW \\
UP & UP & UP & UP \\
\hline $0-10$ & 7 & 14 & 4 & 1 \\
\hline $11-20$ & 2 & 10 & 7 & 2 \\
\hline $21-30$ & 0 & 2 & 10 & 3 \\
\hline $31-40$ & 0 & 1 & 5 & 1 \\
\hline $41-50$ & 0 & 0 & 1 & 0 \\
\hline$>50$ & NA & NA & NA & N \\
\hline TOTAL & 9 & 27 & 27 & 7 \\
\hline
\end{tabular}

Table 4: Data Of Comparison Of Age Group With TBSA Of Burns.

\begin{tabular}{|l|l|l|l|l|l|l|l|}
\hline PERCE & NUMB & NUMB & NUMB & NUMB & NUMB & NUMB & NUMB \\
NTAG & ER OF & ER OF & ER OF & ER OF & ER OF & ER OF & ER OF \\
E OF & PATIE & PATIE & PATIE & PATIE & PATIE & PATIE & PATIE \\
BURN & NTS & NTS & NTS & NTS & NTS & NTS & NTS \\
S & WITH & WITH & WITH & WITH & WITH & WITH & WITH \\
& AGE 0- & AGE & AGE & AGE & AGE & AGE & AGE> \\
& 10 & $11-20$ & $21-30$ & $31-40$ & $41-50$ & $51-60$ & 60 YEA \\
& YEAR & YEAR & YEAR & YEAR & YEAR & YEAR & RS \\
& S & S & S & S & S & S & \\
\hline $0-10$ & 4 & 3 & 2 & 3 & 7 & 3 & 3 \\
\hline $11-20$ & 2 & 0 & 6 & 2 & 8 & 3 & 2 \\
\hline $21-30$ & 0 & 0 & 2 & 3 & 3 & 3 & 6 \\
\hline $31-40$ & 0 & 0 & 2 & 1 & 2 & 0 & 1 \\
\hline $41-50$ & 0 & 0 & 1 & 0 & 0 & 1 & 0 \\
\hline$>50$ & 0 & 0 & 0 & 0 & 1 & 1 & 2 \\
\hline TOTAL & 6 & 3 & 12 & 9 & 21 & 9 & 14 \\
\hline
\end{tabular}

Table5: Parts Of Body Involved In Burns.

\begin{tabular}{|l|l|l|l|l|}
\hline $\begin{array}{l}\text { PERCENTA } \\
\text { GE OF } \\
\text { BURNS }\end{array}$ & $\begin{array}{l}\text { TOTAL } \\
\text { NUMBER } \\
\text { OF } \\
\text { PATIENTS }\end{array}$ & $\begin{array}{l}\text { LOWER } \\
\text { EXTREMIT }\end{array}$ & $\begin{array}{l}\text { UPPER } \\
\text { EXTREMIT } \\
\text { Y }\end{array}$ & $\begin{array}{l}\text { OTHER } \\
\text { AREAS } \\
\text { FACE, } \\
\text { TRUNK } \\
\text { AND BACK }\end{array}$ \\
\hline $0-10$ & 26 & 7 & 19 & 1 \\
\hline $11-20$ & 21 & 9 & 11 & 12 \\
\hline $21-30$ & 15 & 9 & 5 & 8 \\
\hline $31-40$ & 7 & 5 & 3 & 4 \\
\hline $41-50$ & 1 & 1 & 0 & 1 \\
\hline$>50$ & 5 & 5 & 5 & 5 \\
\hline TOTAL & 75 & 36 & 43 & 31 \\
\hline
\end{tabular}

\section{CONCLUSIONS:}

Accidental thermal injuries due to burning of waste are a common practice in outskirts of Kerala. It results in a significant number of admissions in our hospital. It results in significant morbidity, mortality and loss of pay. It is an avoidable injury. Proper preventive measures should be taken by educating target groups to avoid accidental burn injuries due to burning of waste in rural areas. Enactment of laws to make burning of household waste as illegal may prevent it. Proper incineration of waste or recycling of waste or composting may be required to prevent such type of burn injuries. More study on waste management practice is needed to prevent such burn injuries.

\section{Declaration Of Patient Consent}

The authors certify that they have obtained all appropriate patient consent forms. Before doing this study. In the form, the patient(s) has/have given his/her/their consent for his/her image and other clinical information to be reported in the journal. The patients understand that their names and initials will not be published and due efforts will be made to conceal their identity, but anonymity cannot be guaranteed.

\section{Financial Support And Sponsorship:- Nil}

Conflicts Of Interest:- There is no conflict of interest. 
Acknowledgment: We would like to thank our departmental chair for general support and other technical help

\section{REFERENCES}

1. Antonis M. "Wasted Health:The Tragic Case of Dumpsites" International Solid Waste Association, Wien, Austria, June2015.

2. Sharmila D, MahamR.Epidemiology of Burn Injuries: Highlighting Cultural and Socio-Demographic Aspects. Int Rev Psychiatry 2009; 21(6):505-51

3. Navarro F Vincenzo T. Waste Mismanagement in Developing Countries: A Review of Global Issues. Int J Environ Res Public Health 2019; 16:1060.

4. Gupta N., Yadav K.K., Kumar V. A review on current status of municipal solid waste management in India. J. Environ. Sci. (China) 2015;37:206-217.

5. J. L. Gupta, L. K. Makhijal , S. P. Bajaj. National programme for prevention of burn injuries. Indian J PlastSurg 2010; 43(S 01): S6-S10 DOI: 10.1055/s-00391699455Indian J PlastSurg 2010; 43(S 01): S6-S10.DOI: 10.1055/s-00391699455.

6. Forjuoh SN. Burns in low- and middle-income countries: a review of available literature on descriptive epidemiology, risk factors, treatment, and prevention. Burns. 2006;32(5):529-537. doi:10.1016/j.burns.2006.04.002

7. Wibbenmeyer LA, Amelon MA, Loret de Mola RM, Lewis R 2nd, Kealey GP. Trash and brush burning: an underappreciated mechanism of thermal injury in a rural community.J Burn Care Rehabil. 2003 Mar-Apr;24(2):85-9

8. Susan R, Dawn Jones, RN, Sarah Cobb, RN, MS, The Occurrence and Seasonal Variation of Accelerant-Related Burn Injuries in Central Florida, Journal of Burn Care \& Research, Volume 28, Issue 5, September-October 2007. Pages 675-680, https://doi.org/10.1097/BCR.0b013E318148C86E,

9. Atiyeh BS, Costagliola M, Hayek SN.Burn prevention mechanisms and outcomes: pitfalls, failures and successes.Burns. 2009 Mar;35(2):181-93.

10. O.OnubaE,Udoidiok.The problems and prevention of burns in developing countries.Volume 13, Issue 5, October 1987, Pages 382-385

11. Sustainable Solid Waste Management in Developing Countries: Tanzania Outlook." Sustainable Waste Management Challenges in Developing Countries, edited by AgamuthuPariatamby, et al., IGI Global, 2020, pp. 382408. http://doi:10.4018/978-1-7998-0198-6.ch016

12. Srivastava S, Muskaan D. Education in Defining the Usage Pattern of Polybags in the National Capital Region, India. 2019 IJRAR June 2019, Volume 6. Issue 2

13. Villanueva E, Bennett MH, Wasiak J, Lehm JP. Hyperbaric oxygen therapy for thermal burns. Cochrane Database of Systematic Reviews 2004, Issue 2. Art. No.: CD004727. DOI: 10.1002/14651858.CD004727.pub2.

14. Niezgoda JA, Cianci P, Folden BW, et al. The effect of hyperbaric oxygen therapy on a burn wound model in human volunteers. Plastic and Reconstructive Surgery. 1997 May;99(6):1620-1625. DOI: 10.1097/00006534199705000-00023. 